\title{
Unsolved Problem: (Isolated) Systolic Hypertension with Diastolic Blood Pressure below the Safety Margin
}

\author{
Goran Koracevic $^{a, b}$ Milovan Stojanovic ${ }^{c}$ Tomislav Kostic ${ }^{a, b}$ Dragan Lovic ${ }^{d}$ \\ Miloje Tomasevic ${ }^{\mathrm{e}}$ Ruzica Jankovic-Tomasevic ${ }^{a}$ \\ ${ }^{a}$ Department for Cardiovascular Diseases, Clinical Center Nis, Nis, Serbia; ${ }^{b}$ Faculty of Medicine, University of Nis, \\ Nis, Serbia; ' Institute for Treatment and Rehabilitation Niska Banja, Niska Banja, Serbia; ${ }^{d}$ Clinic for Internal Diseases

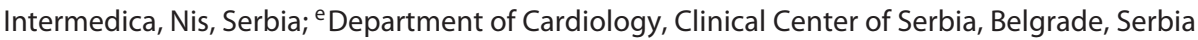

\section{Highlights of the Study}

- A patient with very elevated systolic blood pressure (sBP) and low diastolic blood pressure (dBP) is difficult to treat if one strictly follows the guidelines, as sBP is a clear indication for antihypertensive treatment, but $\mathrm{dBP}<70 \mathrm{~mm} \mathrm{Hg}$ is a relative contraindication.

- We suggest that an adequate search and analysis ought to be performed to solve this problem.

\section{Keywords}

Isolated systolic hypertension · Low diastolic blood pressure $\cdot$ Antihypertensive treatment

\section{Abstract \\ The problem of high systolic blood pressure (sBP) combined with low diastolic blood pressure (dBP) requires attention because SBP is directly and continuously related to the most important criterion, i.e., all-cause mortality, whereas $\mathrm{dBP}$ be- comes inversely related to it after the age of 50-60 years. The European Society of Cardiology and European Society of Hypertension (ESC/ESH) 2018 guidelines for hypertension (HTN) are helpful because they recommend a lower safety cut-off for in-treatment dBP. To prevent tissue hypoperfu- sion, these guidelines recommend that $\mathrm{dBP}$ should be $\geq 70$ $\mathrm{mm} \mathrm{Hg}$ during treatment. A patient with very elevated $\mathrm{sBP}$ (e.g., $220 \mathrm{~mm} \mathrm{Hg}$ ) and low dBP (e.g., $65 \mathrm{~mm} \mathrm{Hg}$ ) is difficult to treat if one strictly follows the guidelines. In this situation, the $\mathrm{sBP}$ is a clear indication for antihypertensive treatment,}

but the $\mathrm{dBP}$ is a relative contraindication (as it is $<70 \mathrm{~mm} \mathrm{Hg}$, a safety margin recognized by the 2018 ESC/ESH guidelines). The dilemma about whether or not to treat isolated systolic hypertension (SH) patients with low $\mathrm{dBP}(<70 \mathrm{~mm} \mathrm{Hg})$ is evident from the fact that almost half $(45 \%)$ remain untreated. This is a common occurrence and identifying this problem is the first step to solving it. We suggest that an adequate search and analysis should be performed, starting from the exploration of the prognosis of the isolated (I)SH subset of patients with a very low $\mathrm{dBP}(<70 \mathrm{~mm} \mathrm{Hg})$ at the beginning of already performed randomized clinical trials.

$$
\begin{aligned}
& \text { (c) } 2020 \text { The Author(s) } \\
& \text { Published by S. Karger AG, Basel }
\end{aligned}
$$

\section{Introduction}

The very challenging situations in medicine are the ones with clear indications and relative contraindications at the same time. Such a situation arises in the treatment of hypertension (HTN). The problem with high systolic

\section{KARGER}

karger@karger.com www.karger.com/mpp
(C) 2020 The Author(s) Published by S. Karger AG, Basel

Karger Open access

This is an Open Access article licensed under the Creative Commons Attribution-NonCommercial-4.0 International License (CC BY-NC) (http://www.karger.com/Services/OpenAccessLicense), applicable to the online version of the article only. Usage and distribution for commercial purposes requires written permission.
Stojanovic Milovan

Department for Cardiovascular Diseases

Institute for Treatment and Rehabilitation Niska Banja

Srpskih junaka, RS-18205 Niska Banja (Serbia)

milovanstojanovic1987@gmail.com 
blood pressure (sBP) combined with low diastolic blood pressure $(\mathrm{dBP})$ requires attention because $\mathrm{sBP}$ is directly and continuously related to the most important criterion, i.e., all-cause mortality, whereas $\mathrm{dBP}$ becomes inversely related to it after the age of 50-60 years [1]. Indeed, the European Society of Cardiology and European Society of Hypertension (ESC/ESH) 2018 guidelines for HTN are very helpful because a lower safety cut-off for in-treatment $\mathrm{dBP}$ is recommended [2].

An unsolved but important clinical problem relates to isolated systolic hypertension ( $\mathrm{SH}$ ), which is believed to result mostly from the stiffening of large arteries [3] (in contrast to essential HTN [E]-HTN, in which a pathologic change/remodeling affects mostly small arteries with a lumen diameter of $100-350 \mu \mathrm{m}$, and arterioles) [4, 5]. Isolated (I)SH is very important because it becomes the most prevalent form of HTN after the age of 50 years $[3,6,7]$. Three-quarters of patients with HTN who are $\geq 70$ years of age have (I)SH [8]. As judged by the US National Health Nutrition Examination Survey (19992006), with a projection to 199.3 million adults, almost $59 \%$ of untreated HTN patients have (I)SH. Their average blood pressure (BP) is $154.3 / 73.8 \mathrm{~mm} \mathrm{Hg}$ [6]. It is important that pretreatment $\mathrm{dBP}$ is on average $73.8 \mathrm{~mm} \mathrm{Hg}$ for the most prevalent type of HTN in patients $>50$ years, i.e., (I])SH, because this $\mathrm{dBP}$ is quite close to the lower safety margin of in-treatment dBP, as suggested by the 2018 ESC/ESH HTN guidelines [2].

(I)SH patients with low $\mathrm{dBP}(<70 \mathrm{~mm} \mathrm{Hg})$ are also common as they constitute around one-third of the (I)SH population (30\% of untreated and $35 \%$ of treated patients) [6]. Almost 4 million Americans with (I)SH have a dBP $<60 \mathrm{~mm} \mathrm{Hg}$ [9]. A low dBP in (I)SH patients is important also because of its association with high-risk features; there is a 3-fold higher prevalence of cardiovascular disease (CVD) in the lowest tertile compared with the highest tertile of dBP in untreated patients with (I)SH [6]. Logistic regression demonstrated that older age, female gender, and diabetes mellitus (DM) are significant predictors of low dBP in (I)SH patients.

The dilemma about whether or not to treat (I)SH patients with low $\mathrm{dBP}(<70 \mathrm{~mm} \mathrm{Hg})$ is evident by the fact that no less than $45 \%$ of them remain untreated $[6,10]$. The relatively high rate of untreated (I)SH with low $\mathrm{dBP}$ is not so surprising if we bear in mind that this lower safety margin (i.e., $\mathrm{dBP}<70 \mathrm{~mm} \mathrm{Hg}$ as set by the 2018 ESC/ESH HTN guidelines) actually corresponds with the BP cut-off for hypotension used in a 2019 study [11]. Interestingly, one-seventh of 12,961 Spanish patients with HTN in primary care had episodes of hypotension, most- ly due to low $\mathrm{dBP}$ (95\%), but low sBP was measured only in $5 \%$ of hypotension. Moreover, antihypertensive druginduced hypotension is a probable explanation for the unexpected finding in a study conducted by Merlo et al. [12]. During 10 years of follow-up of almost 500 elderly men, the incidence of ischemic cardiac events was $>2$-fold greater in those on antihypertensive drugs than in those who were not. The risk of ischemic cardiac events was found to be 4 times higher if $\mathrm{dBP}$ was $<90 \mathrm{~mm} \mathrm{Hg}$ [13].

\section{Results}

Already in 2000, Smulyan and Safar [14] published a recommendation to avoid a marked decrease in $\mathrm{dBP}$ while treating (I)SH. The problem arises because $\mathrm{sBP}$ and $\mathrm{dBP}$ are "inextricably married" [15] and it is very difficult to decrease sBP (aiming to improve prognosis) without reducing $\mathrm{dBP}$ at the same time [15-18].

How Low Must dBP Be to Worse Prognosis (Regarding the Pathophysiology of Coronary Circulation)?

The heart circulation is specific because, during systole, the left ventricle (LV) receives a very small amount of blood (only around 15\%). This is due to the contraction of the muscles of the LV, which are so strong that they compress intramyocardial arteries and arterioles up to the point when the reverse flow (backflow) occurs (at peak systole) $[13,19]$. Consequently, most of the LV perfusion occurs in diastole $[13,20,21]$. Therefore, coronary blood flow depends on pressure (the gradient of dBP between the aorta and LV) and time (the duration of diastole, which is determined by the heart rate [HR]) $[13,22]$. Autoregulation serves to provide relatively constant perfusion of the cardiomyocytes throughout the cardiac cycle, although perfusion pressure may vary largely (45-125 $\mathrm{mm} \mathrm{Hg}$ ) [13]. A specific problem occurs with lower perfusion pressures (below $40-50 \mathrm{~mm} \mathrm{Hg}$ ) because this is when the blood flow to the LV cardiomyocytes stops [13]. HTN itself causes a hypertrophic remodeling of the wall of the coronary arteries (likely increasing the media-tolumen ratio and subsequently diminishing the blood flow) [23]. HTN also promotes constriction of the coronary arterioles (which contributes to myocardial ischemia) [24].

In addition to HTN, an important cause of decreased myocardial perfusion is coronary artery disease (CAD). Despite stenosis of the coronary arteries (up to $70 \%$ of the cross-sectional area), autoregulation can compensate and provide adequate perfusion of the LV cardiomyo- 
cytes. With more severe stenosis, a compromise of myocardial perfusion usually occurs, firstly during effort (and later also during minimal activity or rest). Subsequently, numerous complications linked to ischemia may occur $[13,21]$ including acute myocardial infarction (MI) or a life-threatening arrhythmia, as Berglund [22] recognized already 31 years ago in patients with excessively low BP [23]. In ischemic heart disease (IHD), lower $\mathrm{dBP}$ decreases myocardial perfusion pressure, which activates autoregulation and leads to the dilation of coronary microvessels. When maximal vasodilation cannot compensate anymore, an additional decrease in $\mathrm{dBP}$ (and myocardial perfusion pressure) results in ischemia [25]. Therefore, it is reasonable to expect that low $\mathrm{dBP}$ can render the LV myocardium in IHD patients prone to hypoperfusion and ischemia; the risk reduction obtained by lowering the sBP may be jeopardized by the increased risk arising from the simultaneous lowering of the dBP [18]. A strong pathophysiologic rationale reinforces this concern [15].

An additional difficulty arises with the other important and frequent complication of HTN, i.e., LV hypertrophy (LVH). Hypertrophic LV myocardium requires more $\mathrm{O}_{2}$ and nutrients and can compromise autoregulation, particularly in the subendocardial areas $[13,15]$. The reduced capillary density in LVH further complicates myocardial perfusion [13]. LVH can induce myocardial ischemia by itself (due to the increased $\mathrm{O}_{2}$ need), even in the absence of significant stenosis of the epicardial coronary arteries $[13,15]$. In 1,121 male patients with HTN and electrocardiogram (ECG) signs of LVH, a treatmentinduced lowering of $\mathrm{dBP}$ was associated with a higher risk of IHD events $[15,26]$. Prompt reduction in dBP to $85-90$ $\mathrm{mm} \mathrm{Hg}$ (although not aggressive, according to current beliefs) resulted in LV ischemia in patients with hypertensive LVH $[13,27]$.

Therefore, the combination of HTN with LVH or IHD, particularly during periods of tachycardia, makes patients very prone to an excessive $\mathrm{dBP}$ reduction $[13,25$, $28]$. There is not much to gain by increasing $\mathrm{O}_{2}$ extraction, as this is already very high during rest (70-80\%); the heart is a permanently functioning muscle ("contractile machinery") and it consumes the highest amount of $\mathrm{O}_{2}$ per gram (in the range of $50-100 \mu \mathrm{L} / \mathrm{min} / \mathrm{g}$ ) in comparison with other organs [29]. The additional potential for diminished blood flow in the coronary arteries is not only related to hemodynamics but also to increased thrombogenicity due to raised blood viscosity and the adhesiveness of platelets. It may predispose to acute coronary syndromes [25].

(Isolated) Systolic Hypertension with Low Diastolic BP
Studies Addressing whether Low dBP Related to Worse Prognosis in (I)SH Is a High-Risk Marker and a Cause, or Only a Marker?

As early as 1978, Anderson [29] noted that, in the Framingham Heart Study data, when treating HTN, the benefit of sBP decrease was linear and continuous (there was no "threshold of normality" of sBP). Indeed, this is a motivation to further decrease sBP to lower values. In contrast, no importance was placed on diminishing $\mathrm{dBP}$ below approximately $90 \mathrm{~mm} \mathrm{Hg}$ (a "dog-leg" relation in unsmoothed BP and survival data). This absence of an additional benefit of progressive $\mathrm{dBP}$ decrease (to below approx. $90 \mathrm{~mm} \mathrm{Hg}$ during the 1970s) explains, at least in part, a very important fact, i.e., why sBP has a more significant prognostic influence than $\mathrm{dBP}$ does. Subsequently, in 1979, Stewart [30] demonstrated a $>5$-fold increased mortality rate from MI associated with an excessive (for that time) dBP decrease induced by drug treatment [31]. The BP J-shaped curve debate started 40 years ago, and there is no indication that it will end in the near future. The J-shaped/U-shaped curve means that, for example, mortality is lower at the nadir (the J-point) and that both higher and lower values (e.g., of dBP) are associated with higher mortality.

In the vast majority of studies, the univariate association of low $\mathrm{dBP}$ with worse prognosis has been proved. In many studies, multivariate analysis is missing; in others, results are conflicting regarding this J-curve relationship. Here, we analyze several important studies.

The Hypertension Optimal Treatment (HOT) study, published in 1998, evaluated therapy in 18,790 patients (aged 50-80 years) with HTN and a dBP of $100-115 \mathrm{~mm}$ $\mathrm{Hg}$. The target $\mathrm{dBP}$ was $\leq 90 \mathrm{~mm} \mathrm{Hg}$ in 6,264 patients, $\leq 85 \mathrm{~mm} \mathrm{Hg}$ also in 6,264 patients, and $\leq 80 \mathrm{~mm} \mathrm{Hg}$ in 6,262 patients. In these arms, no significant difference was found in total and cardiovascular (CV) mortality, MI, and stroke risk $[32,33]$. Nevertheless, there is a confirmation of J-curve between major adverse CV events (MACE) and $\mathrm{dBP}$ using additional data about $\mathrm{MI}$ (all plus the silent ones) [34]. The HOT study demonstrated that an intreatment dBP decrease to $82.6 \mathrm{~mm} \mathrm{Hg}$ was beneficial (associated with the lowest rate of MACE); the lowest risk of CV mortality was seen at a dBP of $86.5 \mathrm{~mm} \mathrm{Hg}$. Further lowering of dBP to $70 \mathrm{~mm} \mathrm{Hg}$ was safe, but not additionally useful [34].

In the Atherosclerosis Risk in Communities (ARIC) study, an observational cohort study on 11,565 adults, the authors examined a relationship between BP and MACE. Median follow-up lasted 21 years and patients in whom the $\mathrm{dBP}$ was reduced to $<60 \mathrm{~mm} \mathrm{Hg}$ had a higher mortal-

Med Princ Pract 2020;29:301-309 
ity rate than those with a $\mathrm{dBP}$ of $80-89 \mathrm{~mm} \mathrm{Hg}$. In contrast, the progressive lowering of $\mathrm{dBP}$ resulted in improved stroke prevention [15]. Moreover, although a low sBP was achieved (suggesting an improved prognosis), the authors found a higher concentration of high-sensitive cardiac troponin $\mathrm{T}$ (hs-cTnT) concentration (a wellknown marker of myocardial injury or necrosis) at low $\mathrm{dBP}$ values. A low $\mathrm{dBP}$ and elevated hs-cTnT were associated with MACE, including mortality (but, again, not with stroke). Therefore, even if the optimal sBP is achieved, a substantial amount of residual risk remains that is related to $\mathrm{dBP}$ [16]. At any given SBP, low $\mathrm{dBP}$ was associated with MACE (including mortality); low $\mathrm{dBP}$ was both cross-sectionally and prospectively related to myocardial damage [15]. Lowered basal and in-treatment dBP both had an unfavorable influence on MACE. Therefore, on its own, the low $\mathrm{dBP}$ is a prognosticator. Both causes are important: pretreatment low $\mathrm{dBP}$ (caused by aging and HTN-induced large-artery stiffness) and in-treatment low dBP [15].

The Systolic Blood Pressure Intervention Trial (SPRINT) was a randomized controlled trial (RCT) designed to compare the $\mathrm{CV}$ outcomes of strict sBP control (treatment target $<120 \mathrm{~mm} \mathrm{Hg}$ ) with standard sBP control (treatment target $<140 \mathrm{~mm} \mathrm{Hg}$ ). Median follow-up duration was 3.3 years for 9,361 older adults who had (relatively) high BP $(139.7 \pm 15.6 / 78.1 \pm 11.9 \mathrm{~mm} \mathrm{Hg})$ and an increased risk of CVD. Beddhu et al. [35] demonstrated that patients in the lowest quintile of pretreatment dBP had a higher risk for the primary outcome (the composite $\mathrm{CV}$ outcome) in both treatment groups. Therefore, the $\mathrm{U}$-shaped curve was found for baseline $\mathrm{dBP}$ and primary CVD outcomes in both the intensive and standard treatment arms. More importantly, the benefit of intensive $s B P$ reduction (regarding the primary outcome) was not abolished by baseline dBP level ( $p$ value for interaction $=$ 0.83 ). Consequently, intensive treatment of sBP (which also reduced $\mathrm{dBP}$ ) was beneficial in all subgroups of participants. It was true even for patients who had the lowest baseline $\mathrm{dBP}(<68 \mathrm{~mm} \mathrm{Hg})$, although the average $\mathrm{dBP}$ (achieved during follow-up) in the intensive arm fell to $<60 \mathrm{~mm} \mathrm{Hg}$.

On the other hand, using the SPRINT data, Khan et al. [36] found a J-shaped curve for dBP regardless of treatment arm in 1,519 patients with and 7,574 patients without prior CVD ( $p$ for nonlinearity $\leq 0.002$ ). Models were adjusted for numerous variables. For example, if in-treatment $\mathrm{dBP}$ fell to $<55 \mathrm{~mm} \mathrm{Hg}$, the risk was $68 \%$ higher $(p=0.006)$ than with a dBP of $55-90 \mathrm{~mm} \mathrm{Hg}$ regardless of prior CVD.
Sobieraj et al. [33] published an analysis of 8,890 patients from the SPRINT trial database. They reported a J-shaped curve regarding in-treatment $\mathrm{dBP}$ in hypertensive patients with prior CVD. The primary outcome was more frequently encountered in patients with low $\mathrm{DBP}$, in both the intensive arm (with a dBP in the lowest quintile of $38-61 \mathrm{~mm} \mathrm{Hg}$ ) and the standard treatment arm (with corresponding dBP values of 44-67 $\mathrm{mm} \mathrm{Hg}$ ). In multivariate analysis, low dBP lost its effect on CV risk. The authors' explanation is that the high risk associated with low in-treatment $\mathrm{dBP}$ stemmed mainly from the more advanced age, previous CVD, chronic kidney disease, and a more prevalent smoking habit. They advise that a low $\mathrm{dBP}$ should not preclude treatment to optimal sBP targets. On the other hand, they summarized the available medical evidence regarding J-shaped association between $\mathrm{dBP}$ and $\mathrm{CV}$ risk as being inconclusive.

Other interesting and persuasive evidence emerged from the SPRINT trial database. In 8,046 patients, Lee et al. [37] demonstrated that a low $\mathrm{dBP}(<55 \mathrm{~mm} \mathrm{Hg})$ measured during at least 1 visit was able to predict a significantly increased risk of complications. It is difficult to find an alternative explanation for the J-shaped curve in this analysis, bearing in mind that the authors performed a multivariable Cox proportional analysis.

Böhm et al. [38] merged the data from the Ongoing Telmisartan Alone and in Combination with Ramipril Global Endpoint (ONTARGET) and the Telmisartan Randomized Assessment Study in Angiotensin-Converting Enzyme Inhibitor Intolerant Subjects with Cardiovascular Disease (TRANSCEND) trials, which included patients with a high prevalence of HTN and a high CV risk. They reported that low baseline $\mathrm{dBP}$ values $(<70 \mathrm{~mm} \mathrm{Hg})$ in 5,352 patients were associated with a higher risk than $\mathrm{dBP}>70 \mathrm{~mm} \mathrm{Hg}$ (in 14,305 patients), with regard to allcause death, the composite primary outcome, MI, and hospitalization due to heart failure. The optimal values for both pre- and in-treatment $\mathrm{dBP}$ were around $75 \mathrm{~mm}$ $\mathrm{Hg}$ [16].

The International Verapamil-Trandolapril Study (INVEST) was an open-label, randomized trial with a blinded end point. It recruited 22,576 patients ( $>50$ years). It was optimal for investigating the relationship between low $\mathrm{dBP}$ and mortality risk because all patients had both HTN and stable (chronic) CAD. J-curve association was found between $\mathrm{ABP}$ and primary outcome; patients with a dBP $<75 \mathrm{~mm} \mathrm{Hg}$ had a higher risk of acute MI and death $[33,39]$. The primary outcome was twice as prevalent with a $\mathrm{dBP}<70 \mathrm{~mm} \mathrm{Hg}$ and 4 times as prevalent with a 
$\mathrm{dBP}<60 \mathrm{~mm} \mathrm{Hg}$ [13]. The excessive risk of MI with dBP $<60 \mathrm{~mm} \mathrm{Hg}$ was $14 \%$, higher than the $13 \%$ found with a very high $\mathrm{dBP}(\geq 110 \mathrm{~mm} \mathrm{Hg})[25,39]$. Moreover, the nadir of the J-shaped curve was at 119/84 mm Hg. More importantly, the J-shaped connection between dBP and primary outcome persisted after adjustment. The risk of all-cause death, MI, and the primary outcome gradually increased as dBP became lower. As in (all) other studies, this was not documented for stroke.

Messerli et al. [40] concluded that, in hypertensive patients with CAD, care should be taken to not decrease $\mathrm{dBP}$ excessively. Moreover, the J-curve for $\mathrm{dBP}$ was less pronounced for revascularized than for nonrevascularized CAD patients. This confirms that the J-curve association between $\mathrm{dBP}$ and a poor outcome is strongly related to ischemia.

We have provided a short overview of some of the many studies and analyses published in the last 40 years on the J-curve relationship between $\mathrm{dBP}$ and a worse prognosis. Some potential sources of divergent results about the J-shaped curve are the biases derived from different risks at baseline, different follow-up periods, and the various statistical methods used [23].

On the one hand, there is always apprehension among clinicians about elderly patients who are typical representatives of (I)SH with low dBP; this concern relates to the prevalent comorbidities, the numerous drugs administered, the risk of falls, etc. [41]. Indeed, survival is not the only issue. Analyzing a large sample of 10,355 patients with HTN (with a 30-year follow-up), Lip et al. [42] demonstrated that an increased risk of nonfatal CV events was associated with a low dBP. On the other hand, the benefits of (I)SH treatment are evident and it would be unethical to not utilize contemporary achievements in pharmacology. It is obvious that low $\mathrm{dBP}$ is associated with worse prognosis; this low $\mathrm{dBP}$ is a result of an interplay of numerous etiopathogenic factors, from stiff large arteries to overaggressive BP reduction. Just as Flint et al. [43] concluded from the multivariable Cox survival analysis of no less than 1.3 million adult subjects (from a database of the general outpatient population): there is a J-curve relation between $\mathrm{dBP}$ and $\mathrm{CV}$ prognosis; this J-curve can be partially explained by age.

We have 2 final observations: (1) findings that confirm a J-shaped curve alert us to take care and adjust dBP reduction individually, and (2) other authors do not believe that available evidence is sufficient for a J-shaped curve; they suggest looking carefully for $\mathrm{CV}$ risk factors and comorbidities, because (I)SH patients with a low dBP have several CV risk factors.

(Isolated) Systolic Hypertension with Low Diastolic BP
An Unresolved but Important Clinical Problem: How to Treat Very High sBP with Too Low dBP?

In practice, when we decrease sBP to the target level, we also diminish $\mathrm{dBP}$; if the $\mathrm{dBP}$ level drops too much, we can actually increase mortality in an iatrogenic way. The explanation is simple: when BP is too low ("critically low," e.g., $60 / 30 \mathrm{~mm} \mathrm{Hg}$ ), provided it lasts, this results in tissue hypoperfusion and poor outcomes, although not all studies have confirmed this J-curve phenomenon. A fall in BP is particularly dangerous in patients with hemodynamically significant stenosis of the arteries, because a low prestenotic BP will result in even lower poststenotic pressure. To prevent tissue hypoperfusion, the HTN guidelines recommend that in-treatment $\mathrm{dBP}$ should be $\geq 70 \mathrm{~mm} \mathrm{Hg}$ [2].

There are several scenarios which complicate achieving the target BP including patients' compliance, adherence, and persistence; moreover, therapeutic inertia reduces the success of antihypertensive treatment [2]. Both problems are well recognized and are mostly the physician's or the patient's fault. On the other hand, there are difficulties linked to a patient's status ("objective limitations"). Such intrinsic difficulties are not well acknowledged and ways to address them are lacking, e.g., the common problem of a high pulse pressure (PP). For example, a patient with a very elevated sBP (e.g., $220 \mathrm{~mm} \mathrm{Hg}$ ) and a low $\mathrm{dBP}$ (e.g., $65 \mathrm{~mm} \mathrm{Hg}$ ) is difficult to treat if one strictly follows the guidelines. In this situation, sBP is a clear indication for antihypertensive treatment, but a relative contraindication is $\mathrm{dBP}$ (being $<70 \mathrm{~mm} \mathrm{Hg}$, the safety margin recognized in the $2018 \mathrm{ESC} / \mathrm{ESH}$ guidelines). With the aim of lowering sBP, it is not possible to comply with the recommendation from the guidelines without disregarding the recommendation (from the same guidelines) to not reduce the $\mathrm{dBP}$ to $<70 \mathrm{~mm} \mathrm{Hg}$. To sum up, although important, this issue is not solved (at least as a level of evidence $\mathrm{C}$ recommendation).

Should we administer an antihypertensive drug in (I) SH when $\mathrm{dBP}$ is already (before treatment) under the lower safety margin of $70 \mathrm{~mm} \mathrm{Hg}$ ? In such an extreme situation $(220 / 65 \mathrm{~mm} \mathrm{Hg})$, most physicians will proceed with antihypertensive treatment, even though this would not be adhering completely to the 2018 ESC/ESH guidelines. But what if sBP is not so high? Such patients with (I)SH and an average BP of $175 / 65$ are real and prevalent. They represent one-third of all patients with (I)SH [6], and there are $>4$ million in the USA [9] and many more globally, particularly elderly ones. Should their HTN be treated with antihypertensive drugs? Generally, there is no doubt that (I)SH ought to be treated [2-5]. It is simple to

Med Princ Pract 2020;29:301-309 305 
decide to treat the patient if the official BP is, for example, $175 / 85 \mathrm{~mm} \mathrm{Hg}$, because $\mathrm{sBP}$ is elevated and $\mathrm{dBP}$ is not reduced (and a clear clinical benefit is expected with the reduction of BP). On the other hand, it is not easy to decide on an antihypertensive treatment if $\mathrm{dBP}$ is $65 \mathrm{~mm} \mathrm{Hg}$, because it is below the recommended value not only in 2018 ESC/ESH HTN guidelines but also in many current reviews on the topic. It is outside the scope of the contemporary ESC/ESH guidelines to determine the optimal cutoff for $\mathrm{sBP}$ and the proper time (if it ever comes to that) to start antihypertensive therapy despite a $\mathrm{dBP}$ that is too low (e.g., $65 \mathrm{~mm} \mathrm{Hg}$ ). Is the adequate treatment threshold for sBP $180 \mathrm{~mm} \mathrm{Hg}$, or $170 \mathrm{~mm} \mathrm{Hg}$ if dBP is $65 \mathrm{~mm} \mathrm{Hg}$ ? The absence of this cut-off is the second problem.

To the best of our knowledge, no definite answer to this question has been provided by RCTs. However, it would not be so difficult to take the RCT records of patients who had (I)SH with $\mathrm{dBP}<70 \mathrm{~mm} \mathrm{Hg}$ at baseline and analyze outcomes with pretreatment sBP value as a continuous variable.

\section{Discussion}

\section{Pathophysiology of (I)SH}

Long ago, it was acknowledged that (I)SH is a distinct form of HTN, characterized by an increase in sBP that results mostly from greater stiffness of the large elastic arteries, which occurs with aging $[1,2,44]$. In contrast to E-HTN, neither elevated total peripheral resistance nor mean arterial BP are prerequisites for (I)SH [1]. Aging results in a continuous increase in $\mathrm{sBP}$ while a plateau of $\mathrm{dBP}$ occurs at the age of 50-60 years, followed by a decrease $[21,44]$. At this age, important histological and hemodynamic changes occur in the large arteries, such as inflammation, elastin fragmentation, collagen deposition and calcification, metabolic stress, etc. [45]. Therefore, increasing age is usually associated with aortic stiffening and a raised pulse wave velocity. Consequently, wave reflections (mainly from bifurcations) occur earlier, during late systole (instead of diastole). A reflected wave merges with an anterograde wave in systole (leading to elevated sBP) and not in diastole (which lowers dBP) $[21,24]$.

Increased $\mathrm{sBP}$ with reduced $\mathrm{dBP}$ results in a raised $\mathrm{PP}$ [2]. In addition to the aging process, diminished compliance of the large arteries is a consequence of HTN and atherosclerosis [44]. Therefore, there is a bidirectional relationship, i.e., sBP increases aortic stiffness and vice versa [45].
(I)SH is classified into 2 types, depending on the preexistence of E-HTN. If a patient had E-HTN and then $\mathrm{dBP}$ decreased during aging, it is considered as the "burned-out type." On the other hand, if there was no prior E-HTN and sBP increased while dBP decreased due to an aging-induced increase in stiffness of the large arteries, it is called "de novo (I)SH" [44].

\section{Antihypertensive Therapy of (I)SH Including Patients with Low $d B P$}

The 2019 systematic review and meta-analysis of antihypertensive treatment trials in elderly patients, most of them with (I)SH, demonstrated very good results with the intensive decrease of sBP to $<140 \mathrm{~mm} \mathrm{Hg}$. Allcause mortality was diminished for $24 \%$ and CV mortality for $39 \%$ [46]. This is a very strong impulse to proceed with more intensive treatment, but with caution, because the available clinical trials did not necessarily recruit the frailest patients. Therefore, physicians must consider the important characteristics of an individual patient, such as their cognitive ability, autonomy, and frailty, before determining treatment targets and modalities [46].

The general recommendations for (I) $\mathrm{SH}$ treatment mostly agree in various international and national guidelines. They differ in terms of a class of recommendations and level of evidence, but most guidelines recommend thiazide(-like) diuretics and dihydropyridine calciumchannel blockers (CCBs) [47-51]. The Korean Society also recommends angiotensin-converting enzyme inhibitors or angiotensin-receptor blockers as first-line drugs for (I)SH [52]. Experts in Canada do not recommend $\alpha-1$ $\beta$-blockers as the first choice of antihypertensive drug for (I) SH unless there is a compelling indication [51]. The authors of The National Institute for Health and Care Excellence (NICE) guidelines from Great Britain recommend the same therapy as for other patients with HTN [53].

The authors of the 2018 ESC/ESH HTN guidelines concede that some patients with (I)SH already have a pretreatment $\mathrm{dBP}<80 \mathrm{~mm} \mathrm{Hg}$ (the treatment target). Nevertheless, such (I)SH patients have a high CV risk and so their low dBP should not preclude treatment to attain BP targets (in this case, an sBP of 130-139 mm Hg), but only if the treatment is well tolerated [2]. The authors of Hypertension Canada's 2018 Guidelines recommend caution if $\mathrm{dBP}$ is $<60 \mathrm{~mm} \mathrm{Hg}$, in order to avoid myocardial ischemia [51].

Messerli and Panjrath [13] observed the lack of RCTs directly comparing the effect of antihypertensive drugs 
on "coronary hemodynamic status" in patients with HTN. It is also relevant that renin-angiotensin system (RAS) blockers, CCBs, and diuretics decrease PP, while $\beta$-blockers are less favorable. Moreover, antihypertensive drugs that diminish HR prolong diastole and consequently improve myocardial perfusion. If a patient with (I) $\mathrm{SH}$ has $\mathrm{LVH}$, then antihypertensive classes indicated for reverse LV remodeling (e.g., RAS blockers and CCBs) have the advantage [13].

Indeed, in practice, the decision whether or not to initiate antihypertensive treatment depends on a patient's age, the existence of CAD because coronary flow occurs in diastole, the existence/frequency of drops in BP, previous drops in BP (postural instability), ambulatory blood pressure monitoring (ABPM) results, the patient's preference, etc. In the majority of patients with (I) $\mathrm{SH}$, there is the problem of $\mathrm{dBP}$ potentially diminishing excessively during antihypertensive treatment. This difficulty is prominent in patients with (I)SH and a dBP that is too low, i.e., $<70 \mathrm{~mm} \mathrm{Hg}$. The relevance of this is that (I)SH is very prevalent, particularly in older patients, who are more susceptible to superfluous BP reduction due to numerous comorbidities.

\section{What Are the Gaps in the Knowledge?}

Future studies, which should obtain more precise answers to the problem, should include IHD patients with a known coronary anatomy, the type and completeness of revascularization, and (if possible) the known extent of myocardial ischemia (e.g., obtained by myocardial perfusion scintigraphy). One of the aims should be to find a way to reduce sBP to within the target range, and to then (if needed) optimize dBP because a risk remains (linked to the $\mathrm{dBP}$ ) after the target sBP has been achieved. An analysis of the types and combinations of antihypertensive drugs related to lowered $\mathrm{dBP}$ and the MACE rate is also warranted. Bearing in mind that sBP influences the prognosis the most, it is very important to determine whether, apart from the sBP, the dBP level influences the prognosis more than the class of antihypertensive drugs used, or vice versa.

Simultaneous recordings of Holter ECG and ABPM would give us a more precise insight into the direct provoking mechanisms involved. It would also be useful to see the influence of contemporary IHD management on the J-curve relation between $\mathrm{dBP}$ and mortality in patients with both IHD and (I)SH. Sufficiently large trials are also needed to investigate the J-curve in patients $>60$ years of age with (I)SH, with or without LVH and IHD.

(Isolated) Systolic Hypertension with Low Diastolic BP

\section{Conclusion}

Our aim was to raise awareness about the problem of treating (I)SH patients with $\mathrm{dBP}$ that is too low ( $<70 \mathrm{~mm}$ $\mathrm{Hg}$ according to the latest ESC/ESH 2018 guidelines). In such patients, adequately lowering the sBP is limited because of the parallel excessive lowering of the $\mathrm{dBP}$ (when the $\mathrm{dBP}$ is already too low before the treatment). There is a prevalence of these patients ( $>4$ million in the USA). Moreover, the number of patients with (I)SH is expected to rise proportionally to the increased longevity of the population. We have identified an important problem inherent to some (I)SH patients, namely that it is not possible to follow guideline recommendations completely if the $\mathrm{dBP}$ is too low (below the safety cut-off of $70 \mathrm{~mm} \mathrm{Hg}$ as set by the $2018 \mathrm{ESC} / \mathrm{ESH}$ guidelines). It is a "no-win situation" from the guidelines' perspective: either we leave the sBP too high or lower the $\mathrm{dBP}$ too much. This issue is important for at least 3 reasons: (1) such situations are prevalent, (2) prescribing antihypertensive treatment means disregarding the guidelines' recommendation to not decrease $\mathrm{dBP}$ to below the safety margin and it may lead to harm (and our rule is "first do no harm"), and (3) disregarding recommendations in the guidelines can have legal consequences. It is a common occurrence and identifying the problem is the first step to solving it. We suggest that an adequate search and analysis ought to be performed to solve the issue, starting from the exploration of prognosis of the (I)SH subset of patients with a dBP that is too low $(<70 \mathrm{~mm} \mathrm{Hg})$ at the beginning of already performed RCTs.

\section{Acknowledgement}

This work was supported by the Serbian Ministry of Education and Science, Belgrade, Serbia, grants No.175092 and No. III41018.

\section{Disclosure Statement}

The authors declare no conflict of interest.

References

1 Staessen JA, Gasowski J, Wang JG, Thijs L, Den Hond E, Boissel JP, et al. Risks of untreated and treated isolated systolic hypertension in the elderly: meta-analysis of outcome trials. Lancet. 2000 Mar;355(9207):865-72.

2 Williams B, Mancia G, Spiering W, Agabiti Rosei E, Azizi M, Burnier M, et al.; ESC Scientific Document Group. 2018 ESC/ESH Guidelines for the management of arterial hypertension. Eur Heart J. 2018 Sep;39(33):3021-104. 
3 McEniery CM, Yasmin, Wallace S, Maki-Petaja K, McDonnell B, Sharman JE, et al.; ENIGMA Study Investigators. Increased stroke volume and aortic stiffness contribute to isolated systolic hypertension in young adults. Hypertension. 2005 Jul;46(1):221-6.

4 Schiffrin EL. Remodeling of resistance arteries in essential hypertension and effects of antihypertensive treatment. Am J Hypertens. 2004 Dec;17(12 Pt 1):1192-200.

5 Gutsol AA, Blanco P, Samokhina SI, Afanasiev SA, Kennedy CR, Popov SV, et al. A novel method for comparison of arterial remodeling in hypertension: quantification of arterial trees and recognition of remodeling patterns on histological sections. PLoS One. 2019 May; 14(5):e0216734.

6 Franklin SS, Chow VH, Mori AD, Wong ND. The significance of low DBP in US adults with isolated systolic hypertension. J Hypertens. 2011 Jun;29(6):1101-8.

7 Liu X, Rodriguez CJ, Wang K. Prevalence and trends of isolated systolic hypertension among untreated adults in the United States. J Am Soc Hypertens. 2015 Mar;9(3):197-205.

8 Chobanian AV, Bakris GL, Black HR, Cushman WC, Green LA, Izzo JL Jr, et al.; Joint National Committee on Prevention, Detection, Evaluation, and Treatment of High Blood Pressure. National Heart, Lung, and Blood Institute; National High Blood Pressure Education Program Coordinating Committee. Seventh report of the Joint $\mathrm{Na}$ tional Committee on Prevention, Detection, Evaluation, and Treatment of High Blood Pressure. Hypertension. 2003 Dec;42(6): 1206-52.

9 Tsimploulis A, Sheriff HM, Anker MS, Deedwania P, Fletcher RD, Aronow WS, et al. Treatment of systolic hypertension and low diastolic blood pressure in older adults: how low is too low?! Int J Cardiol. 2017 Sep;242:21.

10 Wang S, Li J, Yan G, Sun M, Zhang Y. Assessment of isolated systolic hypertension with lower diastolic and the risk of cardiovascular disease in older adults. Int J Cardiol. 2017 Sep; 242:20.

11 Divisón-Garrote JA, Prieto-Díaz MÁ, Alonso-Moreno FJ, Velilla-Zancada SM, EscobarCervantes C, Llisterri-Caro JL, et al; Members of the Working Group on Arterial Hypertension and Cardiovascular Disease of SEMERGEN, editors. Prevalence of hypotension in hypertensive treated patients within the primary care setting. The PRESCAP 2010 study. Madrid: Semergen; 2019.

12 Merlo J, Ranstam J, Liedholm H, Hedblad B, Lindberg $G$, Lindblad $U$, et al. Incidence of myocardial infarction in elderly men being treated with antihypertensive drugs: population based cohort study. BMJ. 1996 Aug; 313(7055):457-61.

13 Messerli FH, Panjrath GS. The J-curve between blood pressure and coronary artery disease or essential hypertension: exactly how essential? J Am Coll Cardiol. 2009 Nov;54(20): 1827-34.
14 Smulyan H, Safar ME. The diastolic blood pressure in systolic hypertension. Ann Intern Med. 2000 Feb;132(3):233-7.

15 McEvoy JW, Chen Y, Rawlings A, Hoogeveen RC, Ballantyne CM, Blumenthal RS, et al. Diastolic blood pressure, subclinical myocardial damage, and cardiac events: implications for blood pressure control. J Am Coll Cardiol. 2016 Oct;68(16):1713-22.

16 Böhm M, Schumacher H, Teo KK, Lonn E, Mahfoud F, Mann JF, et al. Achieved diastolic blood pressure and pulse pressure at target systolic blood pressure $(120-140 \mathrm{mmHg}$ ) and cardiovascular outcomes in high-risk patients: results from ONTARGET and TRANSCEND trials. Eur Heart J. 2018 Sep;39(33):3105-14.

17 Topel ML, Sandesara PB, Stahl EP, Hayek SS, Tahhan AS, O'Neal WT, et al. Mechanisms underlying the J-curve for diastolic blood pressure: subclinical myocardial injury and immune activation. Int J Cardiol. 2019 Feb; 276:255-60.

18 Morita K, Mori H, Tsujioka K, Kimura A, Ogasawara Y, Goto M, et al. Alpha-adrenergic vasoconstriction reduces systolic retrograde coronary blood flow. Am J Physiol. 1997 Dec; 273(6):H2746-55.

19 Duncker DJ, Bache RJ. Regulation of coronary blood flow during exercise. Physiol Rev. 2008 Jul;88(3):1009-86.

20 Auer J, Sharman JE, Weber T. J-curves in hypertension: what do they tell us about treatment of high blood pressure? Eur Heart J. 2018 Sep;39(33):3115-8.

21 Sobieraj P, Lewandowski J, Siński M, Symonides B, Gaciong Z. Low Diastolic Blood Pressure is Not Related to Risk of First Episode of Stroke in a High-Risk Population: A Secondary Analysis of SPRINT. J Am Heart Assoc. 2019 Feb;8(4):e010811.

22 Berglund G. Goals of hypertensive therapy; is there a point beyond which pressure reduction is dangerous? Am J Hypertens. 1989 Jul; 2(7):586-93.

23 Drozdz D, Kawecka-Jaszcz K. Cardiovascular changes during chronic hypertensive states. Pediatr Nephrol. 2014 Sep;29(9):1507-16.

24 Banach M, Aronow WS. Blood pressure jcurve: current concepts. Curr Hypertens Rep. 2012 Dec;14(6):556-66.

25 Lindblad U, Råstam L, Rydén L, Ranstam J, Isacsson SO, Berglund G. Control of blood pressure and risk of first acute myocardial infarction: skaraborg hypertension project. BMJ. 1994 Mar;308(6930):681-6.

26 Pepi M, Alimento M, Maltagliati A, Guazzi MD. Cardiac hypertrophy in hypertension. Repolarization abnormalities elicited by rapid lowering of pressure. Hypertension. 1988 Jan; 11(1):84-91.

27 Cruickshank JM. Coronary flow reserve and the J curve relation between diastolic blood pressure and myocardial infarction. BMJ. 1988 Nov;297(6658):1227-30.

28 Goodwill AG, Dick GM, Kiel AM, Tune JD. Regulation of Coronary Blood Flow. Compr Physiol. 2017 Mar;7(2):321-82.
29 Anderson TW. Re-examination of some of the Framingham blood-pressure data. Lancet. 1978 Nov;2(8100):1139-41.

30 Stewart IM. Relation of reduction in pressure to first myocardial infarction in patients receiving treatment for severe hypertension. Lancet. 1979 Apr;1(8121):861-5.

31 Stewart IM. beta-Adrenoceptor blockade and the incidence of myocardial infarction during treatment of severe hypertension. Br J Clin Pharmacol. 1982 Jan;13(1):91-3.

32 Hansson L, Zanchetti A, Carruthers SG, Dahlöf B, Elmfeldt D, Julius S, et al.; HOT Study Group. Effects of intensive blood-pressure lowering and low-dose aspirin in patients with hypertension: principal results of the Hypertension Optimal Treatment (HOT) randomised trial. Lancet. 1998 Jun;351(9118): 1755-62.

33 Sobieraj P, Lewandowski J, Siński M, Gaciong Z. Low on-treatment diastolic blood pressure and cardiovascular outcome: A post-hoc analysis using NHLBI SPRINT Research Materials. Sci Rep. 2019 Sep;9(1):13070.

34 Cruickshank JM. Antihypertensive treatment and the J-curve. Cardiovasc Drugs Ther. 2000 Aug; 14(4):373-9.

35 Beddhu S, Chertow GM, Cheung AK, Cushman WC, Rahman M, Greene T, et al.; SPRINT Research Group. Influence of Baseline Diastolic Blood Pressure on Effects of Intensive Compared with Standard Blood Pressure Control. Circulation. 2018 Jan;137(2): $134-43$.

36 Khan NA, Rabkin SW, Zhao Y, McAlister FA, Park JE, Guan M, et al. Effect of Lowering Diastolic Pressure in Patients with and without Cardiovascular Disease: Analysis of the SPRINT (Systolic Blood Pressure Intervention Trial). Hypertension. 2018 May;71(5): 840-7.

37 Lee TC, Cavalcanti RB, McDonald EG, Pilote L, Brophy JM. Diastolic Hypotension May Attenuate Benefits from Intensive Systolic Targets: Secondary Analysis of a Randomized Controlled Trial. Am J Med. 2018 Oct; 131(10):1228-1233.e1.

38 Böhm M, Schumacher H, Teo KK, Lonn EM, Mahfoud F, Mann JF, et al. Achieved blood pressure and cardiovascular outcomes in high-risk patients: results from ONTARGET and TRANSCEND trials. Lancet. 2017 Jun; 389(10085):2226-37.

39 Pepine CJ, Handberg EM, Cooper-DeHoff RM Marks RG, Kowey P, Messerli FH, et al.; INVEST Investigators. A calcium antagonist vs a non-calcium antagonist hypertension treatment strategy for patients with coronary artery disease. The International Verapamil-Trandolapril Study (INVEST): a randomized controlled trial. JAMA. 2003 Dec;290(21):2805-16.

40 Messerli FH, Mancia G, Conti CR, Hewkin AC, Kupfer S, Champion A, et al. Dogma disputed: can aggressively lowering blood pressure in hypertensive patients with coronary artery disease be dangerous? Ann Intern Med. 2006 Jun;144(12):884-93. 
41 Byrne C, Pareek M, Vaduganathan M, Biering-Sørensen T, Qamar A, Pandey A, et al. Intensive blood pressure lowering in different age categories: insights from the Systolic Blood Pressure Intervention Trial. Eur Heart J Cardiovasc Pharmacother. 2019. DOI: 10.1093/ehjcvp/pvz050.

42 Lip S, Tan LE, Jeemon P, McCallum L, Dominiczak AF, Padmanabhan S. Diastolic Blood Pressure J-Curve Phenomenon in a TertiaryCare Hypertension Clinic. Hypertension. 2019 Oct;74(4):767-75.

43 Flint AC, Conell C, Ren X, Banki NM, Chan SL, Rao VA, et al. Effect of Systolic and Diastolic Blood Pressure on Cardiovascular Outcomes. N Engl J Med. 2019 Jul;381(3):243-51.

44 Umemura S, Arima H, Arima S, Asayama K, Dohi Y, Hirooka Y, et al. The Japanese Society of Hypertension Guidelines for the Management of Hypertension (JSH 2019). Hypertens Res. 2019 Sep;42(9):1235-481.
45 AlGhatrif M, Lakatta EG. The conundrum of arterial stiffness, elevated blood pressure, and aging. Curr Hypertens Rep. 2015 Feb;17(2): 12.

46 Roush GC, Zubair A, Singh K, Kostis WJ, Sica DA, Kostis JB. Does the benefit from treating to lower blood pressure targets vary with age? A systematic review and meta-analysis. J Hypertens. 2019 Aug;37(8):1558-66.

47 Williams B, Poulter NR, Brown MJ, Davis M, McInnes GT, Potter JF, et al; British Hypertension Society. Guidelines for management of hypertension: report of the fourth working party of the British Hypertension Society, 2004-BHS IV. J Hum Hypertens. 2004 Mar; 18(3):139-85.

48 Seedat YK, Rayner BL, Veriava Y; Hypertension guideline working group. South African hypertension practice guideline 2014. Cardiovasc J Afr. 2014 Nov-Dec;25(6):288-94.

49 Task Force of the Latin American Society of Hypertension. Guidelines on the management of arterial hypertension and related comorbidities in Latin America. J Hypertens. 2017 Aug;35(8):1529-45.
50 Tay JC, Sule AA, Chew EK, Tey JS, Lau T, Lee S, et al. Ministry of Health Clinical Practice Guidelines: hypertension. Singapore Med J. 2018 Jan;59(1):17-27.

51 Nerenberg KA, Zarnke KB, Leung AA, Dasgupta K, Butalia S, McBrien K, et al.; Hypertension Canada. Hypertension Canada's 2018 Guidelines for Diagnosis, Risk Assessment, Prevention, and Treatment of Hypertension in Adults and Children. Can J Cardiol. 2018 May;34(5):506-25.

52 Lee HY, Shin J, Kim GH, Park S, Ihm SH, Kim HC, et al. 2018 Korean Society of Hypertension Guidelines for the management of hypertension: part II-diagnosis and treatment of hypertension. Clin Hypertens. 2019 Aug; 25(1):20.

53 The National Institute for Health and Care Excellence. [Internet] NICE guidelines. Hypertension in adults: diagnosis and management (NG136). Available from: https://www. nice.org.uk/guidance/ng136on12/1/2020 